\title{
Recent Advances in Allergen-Specific Immunotherapy as Treatment for Allergic Asthma: A Practical Overview
}

\author{
Ana I. Tabar ${ }^{\mathrm{a}, \mathrm{b}}$ Julio Delgado c Eloina González-Mancebo d, e \\ Esozia Arroabarren $^{\mathrm{a}}$ Lorena Soto Retes ${ }^{\mathrm{f}, \mathrm{g}}$ Javier Domínguez-Ortega ${ }^{\mathrm{h}}$ \\ Spanish Allergy and Clinical Immunology Scientific Society (SEAIC)
}

${ }^{a}$ Department of Allergy, Hospital Complex of Navarra, Pamplona, Spain; ${ }^{\text {b} N a v a r r a ~ I n s t i t u t e ~ f o r ~ H e a l t h ~ R e s e a r c h ~}$ (IdiSNA), Cooperative Health Research Thematic Networks (RETICs) for Asthma, Adverse Reactions to Drugs, and Allergy (ARADYAL) Research Network, Pamplona, Spain; ${ }^{\circ}$ Clinical Management for Allergy Unit, University Hospital Virgen Macarena, Seville, Spain; ${ }^{d}$ Department of Allergy, University Hospital Fuenlabrada, La Paz Hospital Institute for Health Research (IdiPAZ), Madrid, Spain; ' Cooperative Health Research Thematic Networks (RETICs) for Asthma, Adverse Reactions to Drugs and Allergy (ARADYAL) Research Network, Madrid, Spain; 'Department of Pneumology and Allergy, Santa Creu i Sant Pau Hospital, Barcelona, Spain; ${ }^{9}$ Department of Medicine, Sant Pau Biomedical Research Institute (IIB Sant Pau), Autonomous University of Barcelona (UAB), Barcelona, Spain; hepartment of Allergy, La Paz Hospital Institute for Health Research (IdiPAZ), CIBER of Respiratory Diseases, CIBERES, Madrid, Spain

\section{Keywords}

Asthma $\cdot$ Immunotherapy $\cdot$ Allergy $\cdot$ Clinical practice use of AIT in asthma and could facilitate physician clinical decisions and improve health outcomes for individual patients.

(c) 2021 S. Karger AG, Basel

\begin{abstract}
The Global Initiative for Asthma Report updated in 2019 stated that potential benefits of allergen immunotherapy (AIT), compared to pharmacological and avoidance options, must be weighed against the risk of adverse effects and the inconvenience and cost of the prolonged course of therapy in asthma. Thus, with the aim of clarifying some aspects with regard to the possible use of AIT in allergic asthma treatment armamentarium, a group of expert allergists from the Spanish Allergy and Clinical Immunology Scientific Society (SEAIC), particularly from the Immunotherapy and Asthma Interest Groups developed a frequently asked questions in clinical practice. This document updates relevant topics on the
\end{abstract}

\section{Introduction}

Therapy for asthma has substantially evolved in the last years, prompted by a better understanding of the disease pathophysiology and by the characterization of different molecular endotypes and clinical phenotypes, which could favor the implementation of a more personalized therapy [1].

The prevalence of allergic asthma is increasing [2], but current asthma pharmacotherapy is still limited to short-

Edited by: H.-U. Simon, Bern. karger@karger.com www.karger.com/iaa

(c) 2021 S. Karger AG, Basel

Karger ${ }^{\prime}=$
Ana I. Tabar

Department of Allergy, Hospital Complex of Navarra

Navarra Institute for Health Research (IdiSNA)

Calle de Irunlarrea, 3, ES-31008 Pamplona (Spain)

ana.tabar.purroy@cfnavarra.es 
term symptom control with no effect on the underlying immune pathophysiology and, when medication is discontinued, symptoms may recur. This is where allergen immunotherapy (AIT) comes into play as the only management that can alter the natural course of allergic asthma, decreasing frequency and severity of symptoms and progression of rhinitis to asthma [3]. Effective AIT induces multiple immune-mediated mechanisms, which are sequentially activated, leading to allergen-specific tolerance, suppression of inflammation, and multifaceted clinical improvement [4].

Results from recent clinical studies have implemented the evidence of effectiveness and safety of AIT for the treatment of asthma in some cases and, the Global Initiative for Asthma Management and Prevention (GINA) states that potential benefits of AIT, compared to pharmacological and avoidance options, must be weighed against the risk of adverse effects, and the inconvenience and cost of the prolonged course of therapy in asthma [5]. For asthma patients, GINA 2019 considers adding sublingual immunotherapy (SLIT) in adult house dust mite (HDM)-sensitized patients with allergic asthma and exacerbations despite inhaled corticosteroids, provided forced expiratory volume in 1 second (FEV1) is $>70 \%$ predicted and Spanish Asthma Guidelines (Guía Española para el Manejo del Asma [GEMA]) [6] includes the therapeutic option of SLIT with a standardized extract of HDM, prioritizing those that are considered to be a registered medication.

The aim of this paper is to develop a frequently asked questions document that updates relevant topics on the use of AIT in asthma and could facilitate physician work in daily practice. To elaborate the questionnaire, the panel of experts updated and selected all the relevant publications following the same criteria previously published [7] and assessed the level of existing evidence adopting the Oxford Center for Evidence-Based Medicine (OCEBM) [8].

\section{Biomarkers for Monitoring the Asthma AIT Response}

To Date, Are There Any Validated Biomarkers That

Are Predictive or Indicative of the Clinical Response to AIT?

Biomarker, defined as "an indicator of normal biologic processes, pathogenic processes, and/or response to therapeutic or other interventions," remains experimental in AIT [9]. This paucity of biomarkers to aid in the identification of responders to AIT and for the evaluation of its efficacy objectively was recognized in a recent international consensus document [5], which classified it as an unmet need. The European Academy of Allergy and Clinical Immunology (EAACI) recognized this need [10] and established a task force to review all candidate biomarkers used in trials of allergic rhinitis (AR) patients with or without asthma $[9,10]$ including functional (immunoglobulin E [IgE], IgE-facilitated antigen binding [FAB] to $\mathrm{B}$ cells [IgE-FAB] and blocking factor [IgE$\mathrm{BF}]$ ), cellular (regulatory $\mathrm{T}$ and $\mathrm{B}$ cells [Tregs]), humoral (allergen-specific $\operatorname{IgG}_{4}\left[\mathrm{sIgG}_{4}\right], \operatorname{IgE} / \mathrm{IgG}_{4}$ ), and molecular (interleukins) markers. The EAACI's position paper observes that although several studies have included markers as secondary outcomes, specifically AIT biomarker studies are still lacking and concludes that to date there are no validated and generally accepted candidate biomarkers that are predictive or indicative of the response to AIT.

\section{Key Point}

- To date, there are no validated and generally accepted candidate biomarkers that are predictive or indicative of the clinical response to AIT.

\section{Should the Allergen-Specific Serum IgE/Total IgE}

Ratio Be Incorporated in Clinical Practice as a

Predictive Biomarker of Response to AIT?

To date, apart from skin prick tests (SPTs), raised serum allergen sIgE are considered a useful biomarker for AIT candidate selection in the context of a clear history of symptoms on exposure to the relevant allergen [11] and some studies consider sIgE a predictive biomarker for adequate response to AIT [12, 13].In particular, the ratio of sIgE to total $\operatorname{IgE}$ (sIgE/tIgE ratio) as a predictive marker has been evaluated in many clinical trials [14-16]. One of them was carried out in a group of patients who received HDM or grass pollen AIT during 4 years. The study involved both subcutaneous immunotherapy (SCIT) and SLIT treatment [15], and clinical outcome was measured using visual analog scores. A cutoff value of $16.2 \%$ of sIgE/tIgE ratio predicted the successful outcome of AIT, revealing sensitivity of $97.2 \%$ and specificity of $88.1 \%$. Other studies did show a similar correlation between IgE ratio and clinical outcome of AIT, but one randomized controlled trial (RCT) of limited size did not replicate the relationship [14, 16-18]. Therefore, the use of standardized assay platforms, established reference ranges, and cutoff values are needed. 
Key Point

- Basal levels of sIgE help to determine the prescription of AIT in a patient with AR (LE 1b, B). Some studies show that an elevated sIgE/tIgE ratio is a potential biomarker of response to AIT, but the utility has not been evaluated and validated in double-blinded randomized trials (LE $2 b$, grade B).

Could IgG4s Levels and/or the Production of Blocking Antibodies Be Considered as Markers for Compliance in AIT?

Analysis of the regulation of IgG subtypes following AIT has resulted in specific increases (range of 10- to 100fold) in the concentrations of sIgG4 $[19,20]$. In addition, a correlation between allergen SIgG4 and clinical outcomes has been reported in many [21-25] but not all studies [26].

sIgG4 is a serum-based biomarker and indicates allergen exposure. Low sIgG4 is actually considered a potentially negative predictive marker [9]. Additionally, a welldesigned RCT published in 2016 demonstrated a significant increase in allergen sIgG4 in patients with asthma remission treated with HDM-SLIT although a firm relationship between quantitative levels of sIgG4 and clinical standardized efficacy parameters (such as combined symptoms and rescue medication scores) during SCIT/ SLIT are still lacking [21]. Nevertheless, some evidence suggests that functional assays of inhibitory IgG4 and IgE-BF may be more useful surrogates of clinical response than IgG4 levels [27]. In particular, an association between symptom scores, rescue medication scores, and IgE-BF/IgE-FAB has been demonstrated in several studies [28], at least for grass pollen immunotherapy, but there are only limited data on differences between responders and nonresponders in relation to IgE-FAB. The EAACI position paper suggests sIgG4 and IgE-FAB as candidate biomarkers for compliance and response to AIT, respectively, and failure in sIgG4 induction may be indicative of inadequate AIT compliance [9].

\section{Key Points}

- Functional assays of inhibitory IgG4 and IgE-BF may be useful surrogates of clinical response (LE $1 \mathrm{~b}$, grade B); even being aware of the nonavailability in routine clinical practice.

- Failure in sIgG4 induction may be indicative of inadequate AIT compliance (LE 1b, grade B).
With Regard to Biomarkers "in vivo," Could the Challenge Test (or Challenge Test in Allergen

Exposure Chambers) Be Considered as the "Gold Standard" in Clinical Trials II-III of AIT as the EMA Proposes? And in Clinical Practice?

Allergen challenge tests are frequently used in clinical practice to evaluate patients' allergen-specific reactivity in disease affected organs in order to demonstrate the clinical relevance of the underlying IgE-mediated sensitization [29]. These tests have also been used as "in vivo" methods for stratification of patients for clinical trials as well as for investigating the effects of therapeutic interventions in AIT trials. In the current European Medicines Agency (EMA) guideline, challenge tests are recommended for proof of concept or phase II dose-finding trials in AIT [30], and some AIT trials have already included these models as primary objectives [31,32]. Nevertheless, as outlined in the EAACI's position paper, there is a clear unmet need for thorough harmonization and further validation of the different provocation models [33, 34 ], and allergen provocation is not the same as natural exposure.

Regulators do not accept replacement of natural allergen exposures by provocation challenges as primary end points in pivotal phase III trials. The environmental exposure chamber (EEC) represents a recent alternative to challenge tests that more closely simulates natural exposure [35], and it could be a promising tool for the evaluation of efficacy in asthma patients [36], particularly for research purposes in (pivotal) phase III studies. However, they have to be validated regarding stability and reproducibility of allergen exposure under standardized allergens [37]. One of the important aspects to "harmonize" the protocols for challenge tests in EEC is the need to standardize the procedure for each allergen individually since their physicochemical characteristics are different and their clinical behavior is also different. The way of measuring the result (symptoms) should also be standardized on an internationally reproducible scale, and of course, the boxes in the chamber, should be independent to avoid the failures collected in some of the recent clinical trials.

\section{Key Point}

- Protocols of challenge tests/EEC should be harmonized. Pending standardization and clinical validation, EECs are likely to become an optional adjunct to natural exposure studies for phase III trials of AIT (LE 4, grade C). 


\section{Summary}

The identification and validation of biomarkers of successful AIT for allergic asthma are urgently needed to definitively establish the role of AIT as a therapeutic tool in personalized medicine. Until then, functional assays of inhibitory IgG4 and IgE-BF and sIgE/tIgE may be useful surrogates of clinical response.

\section{Etiological Diagnosis prior to Asthma AIT Indication}

What Role Should Molecular Diagnostics Play in

Determining the Sensitization Profile for Defining the

Relevant Allergens in Each Patient?

Different types of aeroallergens and specific sensitization profiles are associated with different allergic clinical pictures (rhinitis with/without asthma), different clinical symptoms, and different levels of severity [38]. Immunotherapy vaccines, in general, consist of different allergen components with a predominance or standardization of major allergens. In many patients originally classified as polysensitized on the basis of SPTs, molecular diagnosis could identify clear sensitizations to particular major allergens with clinical relevance and consequently the allergen sources of which would then have come into consideration for AIT [39]. Molecular diagnosis can also help to identify individuals who are sensitized to minor allergens or to cross-reactive allergens and who therefore may show a different immune response. This allows to better define AIT composition to obtain a greater clinical benefit [40].

The advantage of molecular diagnosis is that it could allow AIT to be individually considered and tailored to each patient and, in some cases, predict the risk of adverse reactions [41] and can spare patients the burden of multiple therapies or unnecessary lifestyle changes involved in allergen avoidance.

Key Points

- Molecular diagnosis can be useful in polysensitized patients in order to identify clear sensitizations to particular allergens with clinical relevance (LE 1b, grade A).

- Molecular diagnosis can help to identify individuals who are sensitized to minor allergens (LE $2 b$, grade B).

Does a Relation between Serum Levels of sIgE and the Risk of Suffering Asthma Exist?

Although IgE-mediated sensitization has been shown to be an important risk factor for allergic asthma, this as- sociation is not consistent. In epidemiology and clinical practice, patients are typically diagnosed as being "sensitized" based on a positive SPT (usually $\geq 3 \mathrm{~mm}$ wheal diameter) or a positive specific serum IgE (usually $>0.35$ $\mathrm{kU} / \mathrm{L}$ ). However, both of these tests can be positive in the absence of any symptoms or disease development. Thus, a clear distinction has to be made between "sensitization" (which usually refers to positive allergy tests, irrespective of any symptoms) and clinical disease such as allergic asthma, which denotes the presence of sensitization and related clinical symptoms.

Independently, the quantity of sIgE may also be a marker of environmental exposure to an antigen, and a positive relationship between the magnitude of exposure to specific aeroallergens and IgE titers have been demonstrated in patients with asthma [42-45]. A recently published study analyzed the association of sIgE levels with the onset of asthma in patients with autumn pollen-induced AR and corroborates that the incidence of asthma is more pronounced when the sIgE level is higher [46]. Thus, if exposure plus sensitization is predictive of asthma morbidity and health care utilization and if the sIgE level is indicative of exposure, then the absolute level of IgE sensitization to allergens may be predictive of the risk of suffering asthma and asthma outcomes. Moreover, a clear quantitative relationship between the level of sIgE and the size of SPT responses has been observed for certain perennial allergens (dust mites or animal dander) in relation to asthma severity, both in young adults and in children $[47,48]$.

\section{Key Point}

- Use level of sIgE for certain perennial allergens as a predictor of health care utilization and asthma morbidity would be a valuable tool for clinicians in the treatment and management of asthma in lieu of, typically unavailable, allergen exposure data (LE 3b, grade B).

\section{Is There Any Possible Role for the Basophil Activation}

Test in the Diagnostic Algorithm of Allergic Asthma and the Use of AIT?

The basophil activation test (BAT) is a reliable tool for detecting basophil activation status "in vitro" and is a promising tool for the diagnosis and monitoring of allergic disease. After the BAT was developed and established, many studies have explored its utility for monitoring AIT responses. Some of the studies have reported that basophil activation is reduced after immunotherapy $[49,50]$, not only at the level of CD63 or CD203c but also as mea- 
sured by decreased diamine oxidase and increased CD107a [50-54]. Furthermore, one study using decreased diamine oxidase has shown persistent suppression of basophil activation 12-24 months after stopping AIT [51]. However, other studies failed to demonstrate suppression of basophil activation in successful trials of AIT [22, 55]. These contrasting findings may be partly explained by the route of immunotherapy, with SLIT being possibly less effective in inhibiting basophils than SCIT and lack of BAT standardization. The International Consensus Statement on Allergy and Rhinology: Allergic Rhinitis published in 2018 considers that BAT could be useful for monitoring response to AIT [56].

\section{Key Point}

- BAT may be used for diagnosis when first-line tests are discordant and for monitoring response to AIT (LE $2 b$, grade B). Standardized assays are needed as markers for basophil selection as well as markers of activation and histamine release.

\section{Summary}

Recognition of the sensitization profile could better define the relevant allergens in each patient and is necessary to perform an adequate etiological diagnosis in asthmatic patients to confirm if we are facing allergic or nonallergic asthma.

\section{Indications/Contraindications of AIT in Asthma Patients}

Should AIT Only Be Considered for the Treatment of Patients with Asthma Whose Symptoms Are Clearly

Linked to a Relevant Allergenic Source?

Current evidence supports the use of AIT for the treatment of patients whose symptoms are clearly linked to a relevant allergenic source [57]. Recommendations from the $\mathrm{GA}^{2} \mathrm{LEN} / \mathrm{EAACI}[58$ ] state that the clinical relevance of each allergen is more important than the number of sensitizations itself. In fact, a personalized AIT is based on the identification of the clinically relevant allergens, one or more, and should consider the type and severity of symptoms, the longest duration of induced symptoms over the year, the greatest impact on quality of life (QoL), and how difficult an allergen is to avoid.
Key Point

- AIT should be considered for the treatment of patients whose symptoms are clearly linked to relevant allergenic sources (EL 1a, grade A).

\section{Can AIT Be Used in Asthmatic Patients with Several}

\section{Sensitizations?}

The majority of patients with allergic asthma seen by specialists are polysensitized, and many of them are also polyallergic (sensitizations with clinical relevance) because polysensitization does not necessarily mean that all sensitivities are clinically significant. In Europe, one or 2 most important sensitivities are typically treated. In contrast, in the United States, mixtures including many or most of the sensitizing allergens are administered [59]. An alternative to allergen mixes for both SLIT and SCIT is the administration of multiple mono-allergen extracts simultaneously or sequentially [60-62].

Single-AIT is recommended in polyallergic patients in which one of the relevant allergens can be identified as clearly responsible for the most intense symptoms [63]. When sensitization to 2 clinically relevant allergens is observed, simultaneous immunotherapy with 2 allergens (SCIT or SLIT) or mixed immunotherapy with 2 allergens is recommended. Allergen mixture immunotherapy may be performed when the mixture is technically feasible, the mixture is allowed by the regulatory authorities, and the concentration of each of the allergens in the final mixture has proven to be effective [63].

\section{Key Point}

- For polysensitized patients with allergic asthma, either mono-AIT or multiple vaccine treatment (allergen mixes or multiple mono-allergen extracts) could be recommended depending on the burden of allergen symptoms (LE 4, grade D, weak recommendation).

Does the Indication of AIT Depend on the Availability of Quality Extracts That Include Concentrations of Allergens Necessary to Induce the Immune Response Necessary for Its Efficacy?

In allergic rhinoconjunctivitis, respiratory allergy [64], and allergic asthma [65] allergens should be accurately quantified in preparations used for AIT. Currently, each allergenic extract's manufacturer has its own standards different from others $[63,66]$. This condition remains one of the main limits of AIT. Nowadays, preparations with a high concentration, good tolerability, and safety, have been included in the official pharmacopoeia, for 
which the concentration of major allergens is provided in $\mu \mathrm{g} / \mathrm{mL}$. In this way, patients would be treated with adequately standardized extracts [67].

\section{Key Point}

- Following the recommendations for AR, allergens should be accurately quantified in preparations used for AIT (LE 1a, grade A).

\section{Is AIT Contraindicated in Partially Controlled Asthma Patients?}

In general, partially controlled asthma is considered a relative contraindication in the EAACI paper although the German guidelines are open to the possibility of using AIT in carefully selected patients [68]. The application of AIT in these patients does not interfere with or substitute the pharmacological treatment for asthma while decreasing the future risk of asthma exacerbations and drug-related adverse events. Moreover, given that effective allergen avoidance is hardly achievable in real-life, AIT offers the opportunity to achieve tolerance to common allergens.

Only AIT with HDM-SLIT tablet has demonstrated a robust effect in adults for critical end points (exacerbations and safety) in partially controlled asthma patients. Thus, it is recommended in the EACCI and GINA guidelines as an add-on to regular asthma therapy for adults with partially controlled HDM-driven allergic asthma [5, 69].

\section{Key Points}

- AIT could be used in carefully selected cases with partially controlled asthma (LE 3, grade C).

- Only HDM-SLIT tablet is recommended as an addon therapy in partially controlled asthma (LE $1 \mathrm{~b}$, grade $\mathrm{B}$ ).

\section{Are There Contraindications in SCIT That Are Not}

Contraindications in SLIT?

Current AIT guidelines recommend that patients with severe or uncontrolled asthma be excluded from consideration for the use of AIT. The major reason for this being that most fatal reactions to SCIT in the past occurred in patients with uncontrolled asthma at the time of the injection $[4,70,71]$. No fatal reactions have been reported to HDM-SLIT tablet, but the indication to start the treatment only in patients with well-controlled asthma remains valid in principle [72]. However, in recent publications and systematic reviews, SLIT has been found to be well tolerated in patients with asthma not well controlled by ICS (400-1,200 $\mu \mathrm{g}$ budesonide or equivalent) [20,73-75] and, given the clinical benefit, it

Allergen-Specific Immunotherapy for

Allergic Asthma appears to be a clinically relevant option in carefully selected cases.

\section{Key Point}

- SCIT/SLIT is indicated in allergic and mild/moderate and well-controlled asthmatic patients (LE $1 \mathrm{~b}$, grade A), and some SLIT preparations (HDM-SLIT tablet) could be an option in severe or partially controlled asthma when the expected benefits can outweigh the potential risks (LE $2 b$, grade $B$ ).

\section{Summary}

AIT is indicated in allergic and well-controlled asthmatic patients and should be considered for the treatment of patients whose symptoms are clearly linked to relevant allergenic sources. Particularly, adequately standardized extracts are recommended. AIT could be used in carefully selected cases with partially controlled asthma.

\section{AIT Efficacy in Adult Asthma Patients}

Does the Use of SCIT Reduce Asthma Symptoms, Asthma Exacerbations, and Asthma Medication in Comparison to Placebo or Symptomatic Treatment?

Several evidence-based reviews and meta-analysis recently published corroborated the improvement in asthma symptoms and medication use with SCIT treatment $[6,67,74,76-83]$ although a lack of homogeneity have been found with regard to the SCIT effect on exacerbations and bronchial responsiveness in comparison to placebo or symptomatic treatment. The lack of uniformity in these analyses can be explained by the heterogeneity in study design and reporting of outcomes, a lack of universally accepted end points, minimal clinically important difference estimates, and differences in the efficacy of allergen preparations in different trials.

SCIT has demonstrated to significantly reduce asthma symptom scores and medication during treatment, but there are important differences between individual allergens, with HDM-SCIT being the allergen with the highest evidence [83-85] (Table 1). In particular, a meta-analysis of 19 studies of SCIT in mite-sensitized subjects with asthma [83] showed that SCIT significantly reduced the asthma symptom scores (standardized mean difference of $-0.94,95 \% \mathrm{CI}-1.58$ to $-0.29, p=0.004)$ and the asthma medication scores (standardized mean difference of $-1.06,95 \%$ CI -1.70 to $-0.42, p=0.001$ ) compared with the control group. Several randomized trials have also evaluated the efficacy of SCIT for grass pollen allergy in 
Table 1. Recommendations for the different AIT allergen sources in allergic asthma

\begin{tabular}{|c|c|c|c|c|c|c|}
\hline $\begin{array}{l}\text { Recommen- } \\
\text { dation }\end{array}$ & $\begin{array}{l}\text { Reduce asthma } \\
\text { symptoms }\end{array}$ & $\begin{array}{l}\text { Reduce asthma } \\
\text { medication }\end{array}$ & $\begin{array}{l}\text { Reduce asthma } \\
\text { exacerbations }\end{array}$ & $\begin{array}{l}\text { Improve lung } \\
\text { function }\end{array}$ & $\begin{array}{l}\text { Improve airway hyper- } \\
\text { reactivity }\end{array}$ & $\begin{array}{l}\text { Improve asthma } \\
\text { control }\end{array}$ \\
\hline HDM AIT & $\begin{array}{l}\text { IA } \\
\text { Strong based on } \\
\text { consistent results } \\
\text { from well- } \\
\text { designed, well- } \\
\text { conducted studies } \\
\text { included in several } \\
\text { SR }\end{array}$ & $\begin{array}{l}\text { IA } \\
\text { Strong based on } \\
\text { consistent results from } \\
\text { well-designed, well- } \\
\text { conducted studies } \\
\text { included in several SR }\end{array}$ & $\begin{array}{l}\text { IB (SLIT) } \\
\text { Moderate based on } \\
\text { results from well- } \\
\text { designed, well- } \\
\text { conducted studies }\end{array}$ & $\begin{array}{l}\text { IB (SLIT) } \\
\text { Weak based on } \\
\text { very limited } \\
\text { number or size of } \\
\text { studies }\end{array}$ & $\begin{array}{l}\text { IA } \\
\text { Strong based on } \\
\text { consistent results from } \\
\text { well-designed, well- } \\
\text { conducted studies } \\
\text { included in several SR }\end{array}$ & $\begin{array}{l}\text { IB (SLIT tablets) } \\
\text { Moderate based on } \\
\text { limited number of } \\
\text { well-designed, } \\
\text { well-conducted } \\
\text { studies }\end{array}$ \\
\hline Grass AIT & $\begin{array}{l}\text { IA } \\
\text { Strong, based on } \\
\text { individual studies }\end{array}$ & $\begin{array}{l}\text { IB } \\
\text { Weak based } \\
\text { Limited number/size of } \\
\text { studies }\end{array}$ & & $\begin{array}{l}\text { IB (SLIT) } \\
\text { Weak based on } \\
\text { very limited } \\
\text { number or size of } \\
\text { studies }\end{array}$ & $\begin{array}{l}\text { IA } \\
\text { Strong based on } \\
\text { consistent results from } \\
\text { well-designed, well- } \\
\text { conducted studies } \\
\text { included in several SR }\end{array}$ & \\
\hline Cat AIT & $\begin{array}{l}\text { IB } \\
\text { Specific } \\
\text { circumstances } \\
\text { RCT weak based }\end{array}$ & $\begin{array}{l}\text { IV D } \\
\text { Very weak based on } \\
\text { expert opinion }\end{array}$ & & & & \\
\hline Dog AIT & $\begin{array}{l}\text { IV D } \\
\text { Specific } \\
\text { circumstances } \\
\text { Expert opinion }\end{array}$ & $\begin{array}{l}\text { IV D } \\
\text { Very weak based on } \\
\text { expert opinion }\end{array}$ & & & & \\
\hline Mold AIT & $\begin{array}{l}\text { IB } \\
\text { Not enough data to } \\
\text { recommend }\end{array}$ & $\begin{array}{l}\text { IB } \\
\text { Weak based and safety } \\
\text { concerns }\end{array}$ & & & & \\
\hline
\end{tabular}

HDM, house dust mite; AIT, allergen immunotherapy; SLIT, subcutaneous immunotherapy.

patients with chest symptoms (breathlessness, cough, wheeze, and chest tightness). The results consistently showed a reduction of asthma symptoms and bronchial hyperresponsiveness [86-88], with long-term effects after the end of treatment $[89,90]$. For other allergens, moderate or low level of evidence exists regarding their impact on asthma [91-94] and depending on the allergen and products used (Table 1).

\section{Key Points}

- SCIT reduces asthma symptoms (LE 1a, grade A) and asthma medications (LE 1a, grade A) in comparison to placebo or symptomatic treatment.
- There are differences between individual allergens in the evidence regarding the reduction of asthma symptoms (LE 1a: HDM, grass; LE 1b: cat, tree; and LE 4d: dog) and use of medication (LE 1a: HDM; LE 1b: grass pollen, mold; and LE $4 \mathrm{~d}$ : cats, dogs).

\section{How Much Time Is Needed to Achieve a Maintained}

Clinical Benefit from AIT in Allergic Asthma Patients?

It is generally accepted that $3-5$ years are required to achieve a clinical benefit and to maintain it after treatment cessation, for either SCIT or SLIT [68], but recent clinical trials $[17,95]$ and meta-analysis [96] have demonstrated that allergen-specific immunotherapy, especially SLIT against HDM may help improve asthma 
symptoms and reduce medication usage for as short as 12 months [97].

The duration of the treatment may be prolonged, depending on the clinical response of subjects. Many patients experience a prolonged remission of symptoms after discontinuation of AIT $[98,99]$, whereas other patients may have a relapse of clinical manifestations. Currently, there are no specific biomarkers or laboratory tests that can distinguish patients who will relapse from those who would have a prolonged clinical remission after discontinuing AIT. In keeping with that evidence, 3 years of SLIT in HDM-sensitized children with asthma had a medication-sparing effect [100]. The data are unclear, with regard to the extent of the medication-sparing effect of AIT, with one study reporting no change in the asthma medication score after 1 year of treatment [95], whereas a pronounced effect was shown in other studies after 1 year of treatment $[17,20,101]$.

Key Point

- AIT treatment should last at least 3 years in asthmatic patients to achieve and to maintain the clinical benefit after treatment cessation (LE 1b, grade A). Clinical benefits can be obtained after 1 year of treatment.

\section{Does SLIT Reduce Asthma Symptoms, Asthma}

Exacerbations, or Asthma Medication in Comparison to Placebo or Symptomatic Treatment?

The evidence reported in relation to the efficacy of SLIT to reduce asthma symptoms, exacerbations, or asthma medication in comparison to placebo or symptomatic treatment in recent systematic reviews and metaanalyses reported moderate evidence based on results from well-designed, well-conducted studies, but with inconsistency between the studies. It is interesting to note, however, that reviews which looked only at a specific allergen (HDM allergen) [102, 103] show significant reductions in both symptom and medication scores for asthma compared to the reviews which focus in several allergens [104-107] that show no significant reduction when considering the same outcomes. Moreover, differences in efficacy with the 2 forms of SLIT (dissolvable sublingual tablets [SLIT tablet] and sublingual allergen extracts [SLIT drops]) have also been described, with the most consistent results obtained with SLIT-tablet formulations [106]. Therefore, differences between different allergens and different formulations could only partially explain the inconsistency.

Allergen-Specific Immunotherapy for

Allergic Asthma
Several individual RCTs have demonstrated the efficacy and safety of SLIT tablets for HDM $[75,80,108-$ 110] and other allergens [111] in asthma. More importantly, the HDM-SLIT tablet is the first allergy immunotherapy to be tested prospectively in a well-designed RCT in patients with HDM allergy-related asthma not well controlled by ICS or combination products and to favorably modify patient relevant end points such as time to first moderate or severe asthma exacerbation upon ICS reduction and reduced risk of an exacerbation with deterioration in asthma symptoms [25]. The potential value of HDM-specific AIT to help step down ICS dosage from GINA step-care levels 3 or 4 [112] and a significantly higher asthma control $(p<0.001)$ and PEF\% $(p<0.05)$ has also been observed in HDM-allergic asthma patients treated with SLIT compared with usual treatment [113]. Consequently, GINA 2017 reports SLIT as a possible add-on option for adults with asthma and AR sensitized to HDM with exacerbations despite low to high doses of inhaled corticosteroids (ICS) provided [73].

The EAACI systematic review data pooled from 2 trials showed no evidence of reduction in the short term of symptom and medication score (SMS), but Lin et al. [114] brought moderately strong body of evidence that SLIT improved SMS (20 of 41 studies). Finally, SLIT, due to its safety profile and efficacy, could be an adequate option for elderly patients because they significantly improve the QoL that often is particularly impaired in the elderly, reducing symptoms and drug consumption [115].

\section{Key Points}

- SLIT reduces asthma symptoms and asthma medication in comparison to placebo or usual care symptomatic treatment (LE $1 \mathrm{~b}$, grade B): (a) SLIT tablets LE 1b, grade B; (b) SLIT drops LE 3a, grade C.

- HDM-SLIT tablet is a possible add-on option for adults with asthma and AR sensitized to HDM with exacerbations despite low to high doses of ICS (LE 1a, grade A).

\section{Summary}

The administration of allergen-specific immunotherapy, both SCIT and SLIT-tablets, is associated with a significant reduction in asthma symptoms and medication, with more evidence demonstrated in patients sensitized to HDM and grass pollen. The HDM-SLIT tablet is a possible add-on option for adults with asthma and AR sensitized to HDM with exacerbations despite

Int Arch Allergy Immunol 2021;182:496-514 503 
low to high doses of ICS. In elderly patients, SLIT, due to its safety profile and efficacy, could be an adequate option.

\section{AIT in Severe Asthma}

\section{Is AIT Expected to Be Less Effective in Severe Asthma}

Patients?

Severe asthma patients could benefit the most from the reduction of allergic asthma symptoms associated with AIT, as demonstrated in a prospective study carried out in children from 3 to 11 years affected with severe asthma [116]. In this study, after 3 years of treatment, children affected with severe asthma and treated with AIT had a significantly greater reduction in terms of days and nights without asthma and drug usage compared with usual drug-treated children; spirometry parameters were also improved. Mainly, the number of SPTs and/or sIgE to inhaled allergens also decreased (desensitization), and the adverse events were only mild or transient. This observation has been confirmed in another 2 pediatric studies in which SCIT with HDM extracts reported beneficial effects for children with moderate to severe asthma, without any child suffering systemic reactions $[117,118]$.

\section{Key Point}

- AIT is not expected to be less efficacious in children with severe controlled asthma patients, and the riskbenefit ratio should be assessed in all cases (LE 3, grade B).

\section{Is AIT Contraindicated in Severe Controlled Asthma}

Patients?

According to current guidelines, AIT is contraindicated in patients with medical conditions that increase the risk of treatment-related systemic reactions, such as those with severe or poorly controlled asthma. Nevertheless, some studies show that severe controlled asthma patients could benefit from the reduction of allergic asthma symptoms and rescue medications associated with AIT, with long-term effects on asthma disease [117, 118].

The recently published EAACI Guideline on AIT-allergic asthma [57] reports a very weak recommendation for not considering AIT in severe asthma due to gaps in the chain of evidence and has established that individual differences between allergens should be considered with HDM inducing less systemic reactions compared to grass and probably molds and animal dander. In addition, to reduce the adverse reactions of AIT and to allow its use in a few patients with severe asthma, some studies demonstrate that pre-administration or concomitant treatment of AIT and omalizumab (an anti-IgE humanized antibody) could be useful [119-122].

\section{Key Point}

- Patients with severe, uncontrolled asthma are at increased risk for systemic reactions. Therefore, AIT should not be initiated administration unless asthma symptoms are controlled (LE 4-5, grade D), and individual differences between allergens should be considered.

\section{Can the Biological Treatment (Omalizumab or}

Others) Be Withdrawn in a Patient with Severe

Asthma and AIT to Continue Only with AIT?

When asthma is controlled, the biologic treatment can be withdrawn because it has been demonstrated that the improvement in the efficacy and tolerability of subcutaneous AIT in children and adults with severe allergic asthma is maintained after biological treatment discontinuation $[4,119,122-124]$.

\section{Key Point}

- The biological treatment (omalizumab or others) could be withdrawn in a patient with severe asthma and AIT to continue only with AIT when asthma is controlled (LE 3b, grade B).

\section{Summary}

The use of omalizumab could improve asthma control and the tolerability of AIT in severe asthmatic patients. AIT is not expected to be less efficacious in severe controlled asthma patients, and the risk-benefit ratio should be assessed in all cases.

\section{Pediatric Asthma and AIT: Some Specific Data}

\section{Does SCIT Reduce Asthma Symptoms, Asthma}

Exacerbations, and Asthma Medication in

Comparison to Placebo or Symptomatic Treatment in Children?

Recent systematic reviews and meta-analysis on AIT for pediatric asthma consistently support the efficacy of both SCIT and SLIT for treatment of pediatric asthma [125-127], but heterogeneity and some methodological inconsistencies are found, especially in outcomes assessment and in the context of individual, real-life setting. In pediatric populations, a higher effect on improvement in 
medication scores and lower effect of AIT on asthma symptoms scores have been described compared to its effect in adult population [65]. A qualitative systematic review that included 40 RCT (25 SCIT trials and 15 SLIT trials) carried out in children ( $<18$ years), which researchers reported on prespecified outcomes, indicated moderate-strength evidence that SCIT reduces long-term asthma medication use. It also showed low-strength evidence that SCIT improves quick-relief medication use, FEV1, and asthma-related QoL. Asthma symptoms were not assessed because there were no trials in which researchers evaluated asthma symptoms using a validated tool [125]. In children, there are 2 important points that should be taken into consideration when making a decision on initiating AIT. The first is the steroid-sparing effect of AIT, which gives a significant advantage for children who have to use ICS doses for the control of asthma symptoms for many years, and the second point is the disease modifying effect of AIT, which reduces the risk of asthma onset in children with AR [99]. The evidence of SCIT on longterm control medication use has been demonstrated in 4 RCT [116, 128-130].

\section{Key Point}

- In children, SCIT reduces asthma symptoms, asthma medication, and exacerbations in comparison to placebo or symptomatic treatment (LE $2 b$, grade B) and could improve long-term asthma control.

\section{Does SLIT Reduce Asthma Symptoms, Asthma}

Exacerbations, and Asthma Medication in

Comparison to Placebo or Usual Care in Children?

The evidence for clinical efficacy of SLIT in children has been assessed in several SR [104, 131], meta-analysis $[132,133]$, and consensus documents [61]. The reviews of the literature on pediatric populations consistently support the efficacy and safety of SLIT compared to placebo, particularly in grass pollen and HDM-sensitized asthmatic children [78]. Similar to SCIT trials carried out in children, SLIT trials are very heterogeneous in patient and intervention characteristics (SLIT tablets vs. SLIT drops, different allergens) and in how outcomes have been measured [125], which limit the ability to draw firm conclusions from them. Relative efficacy of SLIT (symptoms and/or medication score) has been demonstrated in a meta-analysis that included 9 studies on 441 asthmatic children, which shows a significant decrease in symptom and medication scores with SLIT, in comparison to placebo [134]. In another meta-analysis that evaluated 9 studies in 452 HDM-al- lergic children aged 3-18 years with asthma treated with SLIT, marked improvement in asthma symptoms and medication scores, and a steroid-sparing effect was seen [102].

When validated tools to measure outcomes are strictly considered, low-strength evidence for SLIT to improve medication use and FEV1 has been demonstrated, but no evidence for a beneficial effect of SLIT in reducing exacerbations and asthma symptoms [125] has been observed. In particular, no studies reported results on the critical outcomes exacerbations, and 8 RCT were identified to evaluate asthma symptoms [126], but different symptom scores were used, none of them standardized or validated, clinical differences in asthma scores were not defined, and most studies reported improvement in the treatment group as well in the control group.

With regard to the long-term effect of SLIT, 2 studies analyzed this factor in children with allergic asthma/rhinitis due to HDM/grass pollen: The first study considered 2 matched groups: one underwent a 4- to 5-year course of SLIT, and the other received only drug therapy. In the SLIT group, there was a significant difference versus baseline for the presence of asthma and the use of asthma medications, and the mean peak expiratory flow was significantly higher in the active group than in the control group after 10 years [135]. In the second study, asthmatic patients allergic to either HDM or to both HDM and grass pollen were treated with AIT during childhood and were re-evaluated in early adulthood after a mean cessation of AIT of $9.3 \pm 2.76$ years. At re-evaluation, the risk of frequent asthmatic symptoms was 3 times higher in the control group than in the AIT-treated group; the use of anti-asthmatic medication was more pronounced in the control group although the difference was not statistically significant [136]. Finally, a difference in severity between SLIT and placebo on QoL using Childhood Asthma Questionnaires has been observed in one RCT but only in the younger population (age 6-11 years) and it is not stated whether this difference is clinically relevant [137].

\section{Key Point}

- In children, SLIT reduces asthma symptoms and asthma medication in comparison to placebo or symptomatic treatment (a) SLIT tablets LE $2 \mathrm{~b}$, grade B; (b) SLIT drops LE 3a, grade C. 
Are There Some Differences between SCIT/SLIT with Regard to Efficacy and Tolerability in Their Indications in Childhood Asthma?

In children, evidence points to a higher efficacy of SCIT than SLIT, with a better safety profile of SLIT than SCIT. A novel approach for AIT in which SCIT is administered in the build-up phase and SLIT in the maintenance phase might offer better clinical outcomes by integrating their individual advantages to potentiate mechanisms of tolerance. In a randomized, controlled, prospective study in asthmatic children, the novel regimen seems to successfully combine the advantages of both routes without loss of clinical benefit and might be a promising alternative in children undergoing AIT [138].

\section{Key Point}

- SLIT is associated with a better safety profile and lower efficacy than SCIT (LE $2 b$, grade B).

\section{Summary}

In children, SCIT and SLIT reduce asthma symptoms and asthma medication in comparison to placebo or usual care. SLIT is associated with a better safety profile and lower efficacy than SCIT.

\section{Preventive Effects of AIT}

Does Scientific Evidence Support the Indication of AIT for the Prevention of Asthma in Adult Patients with $A R$ ?

Several recent real-world clinical trials [139-141] and the International Consensus Statement on Allergy and Rhinology: Allergic Rhinitis published in 2018 [78] strongly support the use of SCIT (8 studies) and SLIT (25 studies) for patients with AR and asthma as well as the potential utility of AIT for preventing progression of allergic disease from AR to the development of asthma (Level 1a: 2 RCT; Level 1b: 4 RCT; and Level 2b: 1 RCT). When selecting AIT, several aspects must be considered, such as the efficacy and safety of SLIT versus SCIT, specific choice of allergen, and SLIT treatment method (i.e., aqueous drops vs. tablets). AIT, mainly SCIT, represents a preventive strategy against asthma development in adult patients with AR [142, 143], particularly for HDM [144, 145], Parietaria pollen [146] and grass pollen-sensitized patients [82]. A recent observational open study performed in real life confirmed these results in 75 adults with AR to HDM and treated with adjuvanted SLIT, stan- dard SLIT, or drug treatment alone, assessing a preventive effect on pulmonary function over a 5 -year period $(p<0.001)$. After 5 years of treatment, new sensitizations appeared differentially among treatments with $58.1 \%$ of new sensitizations in the drug treatment group, $13.2 \%$ in the standard SLIT patients, and $8.1 \%$ in the adjuvanted SLIT patients [147]. Real-world treatment of AR patients with grass-pollen SLIT tablets has been associated with slower AR progression, less frequent asthma onset, and slower asthma progression $[140,141]$.

\section{Key Point}

- AIT is recommended for the prevention of asthma in adult patients with AR (LE 1a, GRADE A); SCIT (LE $2 \mathrm{~b}$ for HDM, Parietaria and grass pollen); SLIT (LE $2 \mathrm{~b}$ for HDM and $2 \mathrm{~b}$ for grass pollen-associated $\mathrm{AR}$ ).

Does Scientific Evidence Support the Indication of AIT for the Prevention of Asthma in Pediatric Patients with $A R$ ?

According to a recent systematic review, AIT has a significant preventive effect in reducing the development of asthma (risk ratio $0.40,95 \%$ CI $0.30-0.54,5$ trials pooled) [148], particularly if AIT is initiated in childhood, regardless of the modality of AIT (SCIT or SLIT) and allergens used. Long-term studies provided evidence that AIT can favor asthma remission and prevent the onset of asthma in children/adolescents with moderate/severe AR and of new sensitizations [149-153]. The European multicentre Preventive Allergy Treatment study randomized children aged 6-14 years with allergic rhinoconjunctivitis but without asthma who were sensitized to birch and/or grass pollen to SCIT-containing birch and/or grass pollen or to an open control group for 3 years. Subjects who received SCIT were less likely to have asthma at 2 and 7 years after study completion than the control group [151, 153].

With regard to SLIT, the preventive effect on asthma has also been investigated in a prospective study on 60 children allergic to HDM [135]. Patients were divided into 2 groups: 35 treated with SLIT for $4-5$ years and 25 treated only with drugs. Subjects in the treatment group presented a reduced incidence of asthma $(p<0.01)$, while no difference was observed in the control group [135]. The preventive effect of SLIT for pollen has been evaluated in a double-blind placebo-controlled trial, including 812 children with grass pollen-induced rhinoconjunctivitis. After 5 years of therapy with SQ-standardized grass pollen tablets, children in the treatment group presented a reduced risk of developing symptoms of asthma compared to placebo group (OR 0.71, $p<0.05$ ), but SLIT 
treatment did not show an effect on the time to onset of asthma [154].

Key Point

- AIT prevents asthma development in pediatric patients with AR (LE 1b, grade B; SCIT birch/grass $1 \mathrm{~b}$, SLIT HDM, and SLIT grass $2 b$ ).

\section{Is AIT a Cost-Effective Option in Patients with Allergic Asthma?}

A systematic review of AIT health economics found that 23 comparative cost studies provided compelling evidence for the cost savings of AIT (whether SCIT or SLIT) over symptomatic drug treatments for AR associated to asthma [155]. A study assessing SCIT with a high-dose HDM allergoid preparation in children and adolescents with HDM-induced allergic asthma found it to be cost effective on analyzing the drug cost savings 4 years after treatment suspension versus children who had continued with conventional therapy only [156]. More recently, a conservative cost-utility analysis published in 2016 indicated that HDM-SLIT plus pharmacotherapy is cost effective, over a 9-year time period, compared with placebo plus pharmacotherapy, in HDM-allergic asthma patients not well controlled by ICS and associated with mild to severe AR [157]. Thus, there is currently promising evidence that AIT could be a cost-effective option in patients with allergic asthma and assists in stepping down asthma controller treatment favoring asthma control, preventing bronchial asthma and new sensitizations.

\section{Summary}

AIT (SCIT and SLIT) may be considered for the benefit of preventing the progression of AR to asthma in patients with AR only.

\section{Discussion and Concluding Remarks (Table 2)}

Even though AIT was first described more than a century ago and numerous clinical trials and meta-analyses have been carried out proving AIT efficacious in allergic asthma, it still remains underused [4]. The major barriers for the further development of AIT in clinical practice are the lack of phase 3 confirmatory, double-blind, placebocontrolled trials per specific allergen source in well-defined patients and using validated outcomes. Studies of AIT in asthma should include only patients with allergic asthma and should be performed following standardized protocols, with a focus on the long-term and preventive

Allergen-Specific Immunotherapy for

Allergic Asthma effects of the treatment [158]. In relation to this topic, parameters that analyzed the possible impact on long-term asthma pathophysiology are of relevant interest, such as lung function or asthma control. Moreover, according to the European Medicines Agency (EMA), clinical trials on AIT in asthmatic patients begin as add-on therapy and this fact should be considered in the evaluation of the primary end point. Validated parameters of asthma control such as the Asthma Control Test (ACT), Asthma Control Questionnaire (ACQ), or Asthma Quality of Life Questionnaire (AQLQ)] should be used. A reduced need for controlled medication, number of exacerbations, or time to first exacerbation could be considered as primary end points. Some efforts have been made taking all these points into consideration, and nowadays, validated evidence have been published for HDM-SLIT in adults, which has been translated into considering HDM-specific AIT to help step-down ICS dosage from GINA stepcare levels 3 or 4 [102]. The design and primary end point of the most recent studies are in line with the latest EMA guidance on AIT products, intended to modify the immunologic mechanism underlying allergic asthma [159]. Efficacy and safety data meet the demands for robust evidence from well-conducted, randomized clinical trials called for in guidelines, reviews, and meta-analyses. The ARIA guideline noted that new data from rigorously designed and executed randomized trials of SLIT in children would likely have an important effect on recommendations for the use of SLIT in children with allergic asthma and AR.

In the pediatric population, determination of the best time to start AIT is an important point, as early therapeutic intervention with AIT when the child is in the early stages of the respiratory disease and still mono- or paucisensitized, can be evaluated as a relevant therapeutic option in the clinical practice. The efficacy/safety profile of AIT and adequate dosage with standardized extracts should also be considered when selecting the therapy $[160,161]$. Recent studies suggest a decrease in systemic reactions with SCIT associated to a better selection of patients and adequate use of AIT in well-controlled asthma patients, independently of the severity of asthma [162165]. Also, a need for harmonization in the classification of systemic adverse reactions among the different AIT gradingsystems(EASSI-severity,EAACI2006, WAO2010, WAO2017, and AAAAI/ACAAI Grading System) has been indicated [166]. The use of biologics to decrease possible risks is also an option in these patients.

Finally, patient-related outcome measures, such as health cost end points and QoL that impact on benefit/ 
Table 2. Summary of recommendations/conclusions

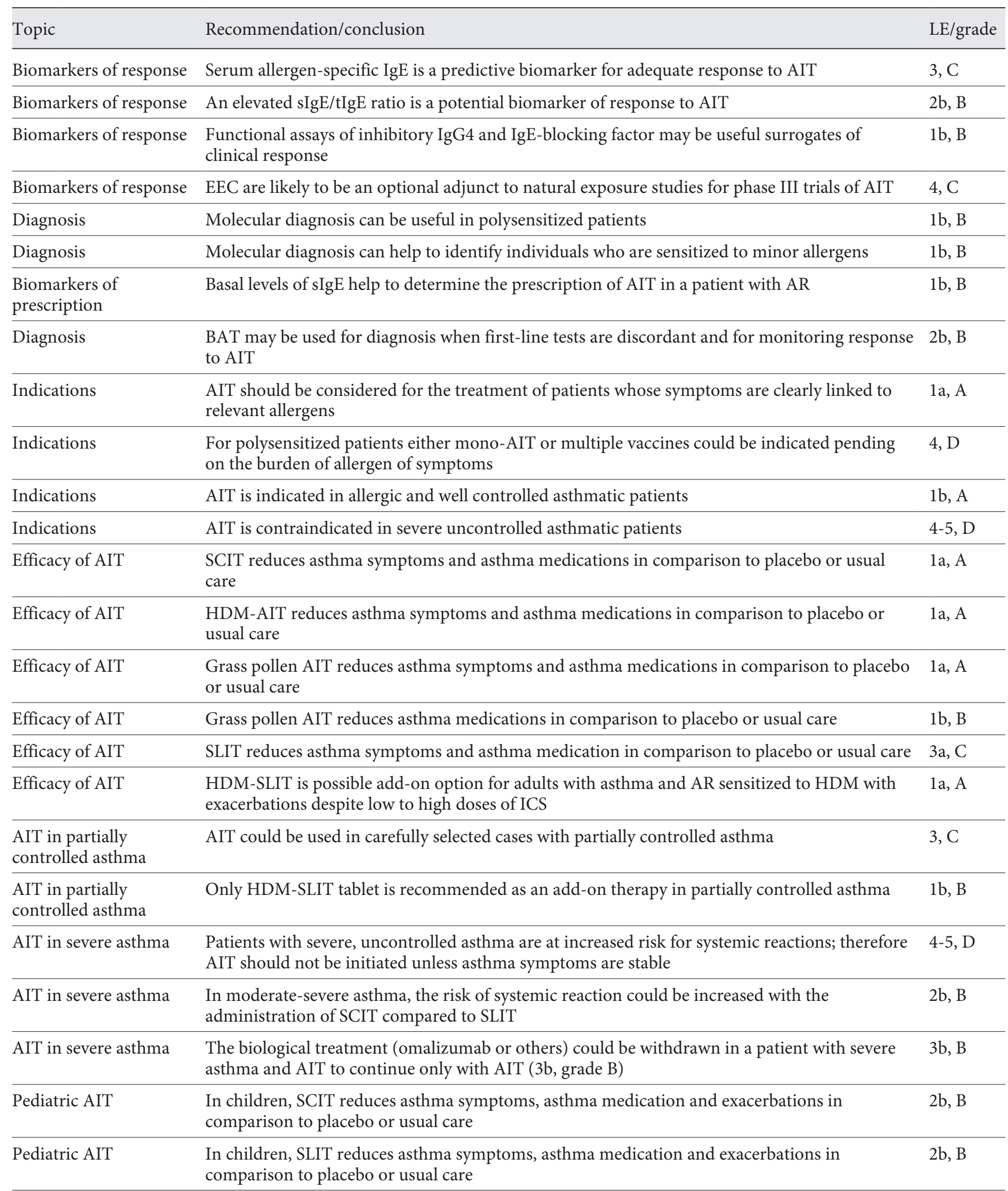


Table 2 (continued)

\begin{tabular}{|c|c|c|}
\hline Topic & Recommendation/conclusion & LE/grade \\
\hline Pediatric AIT & SLIT is associated with a better safety profile and lower efficacy than SCIT & $2 \mathrm{~b}, \mathrm{~B}$ \\
\hline Preventive effect of AIT & AIT prevents asthma development in pediatric patients with allergic rhinitis & $1 b, B$ \\
\hline Preventive effect of AIT & $\begin{array}{l}\text { In adults, SCIT for HDM, Parietaria pollen and grass pollen-associated AR prevents asthma } \\
\text { development }\end{array}$ & $2 b, B$ \\
\hline Preventive effect of AIT & In adults, SLIT for HDM and for grass pollen-associated AR prevents asthma development & $2 \mathrm{~b}, \mathrm{~B}$ \\
\hline Preventive effect of AIT & In pediatric patients, SCIT for birch/grass pollen-associated AR prevents asthma development & $1 \mathrm{~b}, \mathrm{~B}$ \\
\hline Preventive effect of AIT & $\begin{array}{l}\text { In pediatric patients, SLIT for HDM and for grass pollen-associated AR prevents asthma } \\
\text { development }\end{array}$ & $2 \mathrm{~b}, \mathrm{~B}$ \\
\hline
\end{tabular}

AR, allergic rhinitis; AIT, allergen immunotherapy; HDM, house dust mite; LE, level of evidence; ICS, inhaled corticosteroids; SCIT, subcutaneous immunotherapy; SLIT, sublingual immunotherapy.

risk assessment are of special interest [167]. The cost-effectiveness findings of AIT in asthma depend on the duration of the clinical benefit after treatment suspension and the balance between the direct costs of AIT during its maintenance phase and the drug cost savings afforded by the introduction of AIT. It is important to further explore this effect so that affected individuals can benefit from this treatment. Thus, more well-designed studies with other allergen products and well-defined populations are encouraged.

\section{Acknowledgements}

The authors would like to acknowledge Dra. Ana Isabel Ortega and Ana-María Zabaljauregui who provided medical writing support on behalf of Springer Healthcare, with funding from ALKAbelló.

\section{Conflict of Interest Statement}

Ana I. Tabar has received advisor and speaker's honoraria from ALK-Abelló, Allergy Therapeutics, Astra, Diater, GSK, Inmunotek, InnoUp, Leti, Merck, Mundipharma, \& Novartis; she has participated in research projects sponsored by Leti \& Merck. Julio Delgado, in the last 3 years, has been on advisory boards for Sanofi and Mundipharma and received speaker's honoraria from AstraZeneca, Chiesi, GlaxoSmithKline, Merck, and Pfizer, has received help assistance to meeting travel from Menarini and Novartis, and has participated in research projects sponsored by Merck. Eloina González Mancebo has received advisor and speaker's honoraria from ALK-Abelló, Merck, AstraZeneca,
Mundipharma, Novartis, GSK, Allergy Therapeutics, and Stallergenes-Greer and has participated in research projects sponsored by Leti and Roxall. Esozia Arroabarren has received speaker's honoraria from ALK-Abelló and travel support from ALKAbello, Leti, Roxall, and HAL. Lorena Soto-Retes declares that in the last 3 years has received fees for lectures or grants to attend conferences and scientific meetings by GSK, Menarini, FAES, Astrazeneca, Chiesi, Mundipharma, Stallergennes, Leti, Hal-Allergy, Allergy Therapeutics, and Immunotek and received funding/grant support for research projects from not-for-profit foundations SEAIC (Sociedad Española de Alergia e Inmunología Clínica) and SEPAR (Sociedad Española de Neumología y Cirugía Torácica).

Javier Domínguez-Ortega has participated in advisory boards and acted as a consultant for ALK-Abelló, Allergy Therapeutics, LETI, and Stallergenes; he has received speaker's honoraria from TEVA, MundiPharma, and GSK.

\section{Funding Sources}

This work was funded by ALK-Abelló without participating in its design, analysis of data, or preparation of the manuscript.

\section{Author Contributions}

All the authors have contributed significantly in the literature search, writing and revision of the manuscript and have approved the submitted version. A.T. has thoroughly reviewed the final version of the manuscript. 


\section{References}

1 Ciprandi G, Tosca MA, Silvestri M, Ricciardolo FLM. Inflammatory biomarkers for asthma endotyping and consequent personalized therapy. Expert Rev Clin Immunol. 2017; 13(7):715-21.

2 Backman H, Räisänen P, Hedman L, Stridsman C, Andersson M, Lindberg A, et al. Increased prevalence of allergic asthma from 1996 to 2006 and further to 2016-results from three population surveys. Clin Exp Allergy. 2017;47(11):1426-35.

3 Jutel M, Agache I, Bonini S, Burks AW, Calderon $\mathrm{M}$, Canonica $\mathrm{W}$, et al. International consensus on allergy immunotherapy. J Allergy Clin Immunol. 2015;136(3):556-68.

4 Jutel M, Agache I, Bonini S, Burks AW, Calderon $\mathrm{M}$, Canonica W, et al. International Consensus on Allergen Immunotherapy II: mechanisms, standardization, and pharmacoeconomics. J Allergy Clin Immunol. 2016;137(2): 358-68.

5 Global Initiative for Asthma. Global strategy for asthma Management and prevention 2019. Available from: www.ginaasthma.org/.

6 GEMA 4.4: Guía Española para el Manejo del Asma 2019. Available from: https://www. semg.es/index.php/consensos-guias-yprotocolos/316-gema-4-4-guia-espanola-para-el-manejo-del-asma.

7 Domínguez-Ortega J, Delgado J, Blanco C, Prieto L, Arroabarren E, Cimarra M, et al. Specific allergen immunotherapy for the treatment of allergic asthma: a review of current evidence. J Investig Allergol Clin Immunol. 2017;27(Suppl 1):1-35.

8 Phillips B, Chalmers I, Sackett D, Badenoch D, Straus S, Haynes B, et al. Oxford centre for evidence-based medicine: levels of evidence (March 2009).

9 Shamji MH, Kappen JH, Akdis M, Jensen-Jarolim E, Knol EF, Kleine-Tebbe J, et al. Biomarkers for monitoring clinical efficacy of allergen immunotherapy for allergic rhinoconjunctivitis and allergic asthma: an EAACI position paper. Allergy. 2017;72(8):1156-73.

10 Berings M, Karaaslan C, Altunbulakli C, Gevaert $\mathrm{P}, \mathrm{Akdis} \mathrm{M}$, Bachert $\mathrm{C}$, et al. Advances and highlights in allergen immunotherapy: on the way to sustained clinical and immunologic tolerance. J Allergy Clin Immunol. 2017; 140(5):1250-67.

11 Tosca M, Silvestri M, Sivestri M, Accogli A, Rossi GA, Ciprandi G. Serum-specific IgE and allergen immunotherapy in allergic children. Immunotherapy. 2014;6(1):29-33.

12 Ciprandi G, Alesina R, De Amici M. Serum specific IgE: biomarker for specific immunotherapy responsiveness? Allergol Immunopathol. 2014;42(4):369-71.

13 Ciprandi G, Silvestri M, Sivestri M. Serum specific IgE: a biomarker of response to allergen immunotherapy. J Investig Allergol Clin Immunol. 2014;24(1):35-9.
14 Li Q, Li M, Yue W, Zhou J, Li R, Lin J, et al. Predictive factors for clinical response to allergy immunotherapy in children with asthma and rhinitis. Int Arch Allergy Immunol. 2014;164(3):210-7.

15 Di Lorenzo G, Mansueto P, Pacor ML, Rizzo M, Castello F, Martinelli N, et al. Evaluation of serum s-IgE/total $\mathrm{IgE}$ ratio in predicting clinical response to allergen-specific immunotherapy. J Allergy Clin Immunol. 2009; 123(5):1103-4.

16 Karakoc GB, Yilmaz M, Altıntaş DU, Kendirli SG. Can serum-specific IgE/total IgE ratio predict clinical response to allergen-specific immunotherapy in children monosensitized to house dust mite? J Allergy. 2012;2012:1.

17 Wurtzen PA, Lund G, Lund K, Arvidsson M, Rak S, Ipsen H. A double-blind placebo-controlled birch allergy vaccination study II: correlation between inhibition of IgE binding, histamine release and facilitated allergen presentation. Clin Exp Allergy. 2008;38:1290-301.

18 Eifan AO, Akkoc T, Yildiz A, Keles S, Ozdemir C, Bahceciler NN, et al. Clinical efficacy and immunological mechanisms of sublingual and subcutaneous immunotherapy in asthmatic/rhinitis children sensitized to house dust mite: an open randomized controlled trial. Clin Exp Allergy. 2010;40(6): 922-32.

19 Jutel M, Jaeger L, Suck R, Meyer H, Fiebig H, Cromwell O. Allergen-specific immunotherapy with recombinant grass pollen allergens. J Allergy Clin Immunol. 2005;116(3):608-13.

20 Reisinger J, Horak F, Pauli G, van Hage M, Cromwell O, König F, et al. Allergen-specific nasal IgG antibodies induced by vaccination with genetically modified allergens are associated with reduced nasal allergen sensitivity. J Allergy Clin Immunol. 2005;116(2):347-54.

21 Virchow JC, Backer V, Kuna P, Prieto L, Nolte $\mathrm{H}$, Villesen $\mathrm{HH}$, et al. Efficacy of a house dust mite sublingual allergen immunotherapy tablet in adults with allergic asthma: a randomized clinical trial. JAMA. 2016;315(16):1715-25.

22 Gomez E, Fernandez TD, Dona I, Rondon C, Campo P, Gomez F, et al. Initial immunological changes as predictors for house dust mite immunotherapy response. Clin Exp Allergy. 2015;45:1542-53.

23 Gehlhar K, Schlaak M, Becker W, Bufe A. Monitoring allergen immunotherapy of pollen-allergic patients: the ratio of allergen-specific IgG4 to IgG1 correlates with clinical outcome. Clin Exp Allergy. 1999;29(4):497-506.

24 Moverare R, Elfman L, Vesterinen E, Metso T, Haahtela T. Development of new IgE specificities to allergenic components in birch pollen extract during specific immunotherapy studied with immunoblotting and Pharmacia CAP System. Allergy. 2002;57:423-30.
25 Nelson HS, Nolte H, Creticos P, Maloney J, Wu J, Bernstein DI. Efficacy and safety of timothy grass allergy immunotherapy tablet treatment in North American adults. J Allergy Clin Immunol. 2011;127(1):72-2.

26 Jarolim E, Poulsen LK, Stadler BM, Mosbech $\mathrm{H}$, Oesterballe $\mathrm{O}$, Kraft D, et al. A long-term follow-up study of hyposensitization with immunoblotting. J Allergy Clin Immunol. 1990; 85(6):996-1004.

27 Suárez-Fueyo A, Ramos T, Galán A, Jimeno L, Wurtzen PA, Marin A, et al. Grass tablet sublingual immunotherapy downregulates the TH2 cytokine response followed by regulatory T-cell generation. J Allergy Clin Immunol. 2014;133(1):130-2.

28 Shamji MH, Ljørring C, Francis JN, Calderon MA, Larché M, Kimber I, et al. Functional rather than immunoreactive levels of IgG4 correlate closely with clinical response to grass pollen immunotherapy. Allergy. 2012; 67(2):217-26.

29 Bousquet J, Khaltaev N, Cruz AA, Denburg J, Fokkens WJ, Togias A, et al. Allergic rhinitis and its impact on asthma (ARIA) 2008 update (in collaboration with the World Health Organizat3(2)LEN and Aller-Gen). Allergy. 2008;63(Suppl 86):8-160.

30 CHMP EMA Guideline on the Clinical Development of Products for Specific. Immunotherapy for the Treatment of Allergic Diseases. 2008.

31 Pfaar O, van Twuijver E, Boot JD, Opstelten DJ, Klimek L, van Ree R, et al. A randomized DBPC trial to determine the optimal effective and safe dose of a SLIT birch pollen extract for the treatment of allergic rhinitis: results of a phase II study. Allergy. 2016;71:99-107.

32 Makatsori M, Pfaar O, Calderon MA. Allergen immunotherapy: clinical outcomes assessment. J Allergy Clin Immunol Pract. 2014; 2(2):123-30.

33 Pfaar O, Demoly P, Gerth van Wijk R, Bonini S, Bousquet J, Canonica GW, et al. Recommendations for the standardization of clinical outcomes used in allergen immunotherapy trials for allergic rhinoconjunctivitis: an EAACI position paper. Allergy. 2014;69(7): 854-67.

34 Pfaar O, Calderon MA, Andrews CP, Angjeli E, Bergmann KC, Bønløkke JH, et al. Allergen Exposure Chambers (AEC): harmonizing current concepts and projecting the needs for the future: an EAACI position paper. Allergy. 2017 Jan [cited 2017 Mar 1]

35 Jacobs RL, Harper N, He W, Andrews CP, Rather CG, Ramirez DA, et al. Responses to ragweed pollen in a pollen challenge chamber versus seasonal exposure identify allergic rhinoconjunctivitis endotypes. J Allergy Clin Immunol. 2012;130(1):122-e8. 
36 Zieglmayer P, Nolte H, Nelson HS, Bernstein DI, Kaur A, Jacobi H, et al. Long-term effects of a house dust mite sublingual immunotherapy tablet in an environmental exposure chamber trial. Ann Allergy Asthma Immunol. 2016;117(6):690-e1.

37 Pfaar O, Bastl K, Berger U, Buters J, Calderon MA, Clot B, et al. Defining pollen exposure times for clinical trials of allergen immunotherapy for pollen-induced rhinoconjunctivitis: an EAACI position paper. Allergy. 2017; 72(5):713-22.

38 Valero A, Quirce S, Dávila I, Delgado J, Domínguez-Ortega J. Allergic respiratory disease: different allergens, different symptoms. Allergy. 2017;72(9):1306-16.

39 Stringari G, Tripodi S, Caffarelli C, Dondi A, Asero R, Di Rienzo Businco A, et al. The effect of component-resolved diagnosis on specific immunotherapy prescription in children with hay fever. J Allergy Clin Immunol. 2014; 134(1):75-81.

40 Valenta R, Twaroch T, Swoboda I. Component-resolved diagnosis to optimize allergenspecific immunotherapy in the Mediterranean area. J Investig Allergol Clin Immunol. 2007;17(Suppl 1):36-40.

41 Sastre J, Sastre-Ibañez M. Molecular diagnosis and immunotherapy. Curr Opin Allergy Clin Immunol. 2016;16(6):565-70.

42 Wang J, Visness CM, Calatroni A, Gergen PJ, Mitchell HE, Sampson HA. Effect of environmental allergen sensitization on asthma morbidity in inner-city asthmatic children. Clin Exp Allergy. 2009;39(9):1381-9.

43 Chew GL, Perzanowski MS, Canfield SM, Goldstein IF, Mellins RB, Hoepner LA, et al. Cockroach allergen levels and associations with cockroach-specific IgE. J Allergy Clin Immunol. 2008;121(1):240-5.

44 Gruchalla RS, Pongracic J, Plaut M, Evans R III, Visness CM, Walter M, et al. Inner city asthma study: relationships among sensitivity, allergen exposure, and asthma morbidity. J Allergy Clin Immunol. 2005;115(3):478-85.

45 Lewis SA, Weiss ST, Platts-Mills TA, Burge H, Gold DR. The role of indoor allergen sensitization and exposure in causing morbidity in women with asthma. Am J Respir Crit Care Med. 2002;165(7):961-6.

46 Cui L, Yin J. Association of serum specific IgE levels with asthma in autumn pollen-induced allergic rhinitis: a retrospective analysis. J Asthma. 2018;18:1-7.

47 Frith J, Fleming L, Bossley C, Ullmann N, Bush A. The complexities of defining atopy in severe childhood asthma. Clin Exp Allergy. 2011;41(7):948-53.

48 Just J, Gouvis-Echraghi R, Rouve S, Wanin S, Moreau D, Annesi-Maesano I. Two novel, severe asthma phenotypes identified during childhood using a clustering approach. Eur Respir J. 2012;40:55-60.
49 Erzžen R, Košnik M, Silar M, Korošec P. Basophil response and the induction of a tolerance in venom immunotherapy: a long-term sting challenge study. Allergy. 2012;67:822-30.

50 Gokmen NM, Ersoy R, Gulbahar O, Ardeniz $\mathrm{O}$, Sin A, Unsel M, et al. Desensitization effect of preseasonal seven-injection allergoid immunotherapy with olive pollen on basophil activation: the efficacy of olive pollen-specific preseasonal allergoid immunotherapy on basophils. Int Arch Allergy Immunol. 2012; 159(1):75-82.

51 Shamji MH, Layhadi JA, Scadding GW, Cheung DK, Calderon MA, Turka LA, et al. Basophil expression of diamine oxidase: a novel biomarker of allergenimmunotherapy response. J Allergy Clin Immunol. 2015;135: 913-21.

52 Zidarn M, Košnik M, Šilar M, Bajrović N Korošec P. Sustained effect of grass pollen subcutaneous immunotherapy on suppression of allergen-specific basophil response; a real-life, nonrandomized controlled study. Allergy. 2015;70(5):547-55.

53 Lalek N, Kosnik M, Silar M, Korosec P. Immunoglobulin G-dependent changes in basophil allergen threshold sensitivity during birch pollen immunotherapy. Clin Exp Allergy. 2010;40(8):1186-93.

54 Nopp A, Cardell LO, Johansson SG, Oman H. CD-sens: a biological measure of immunological changes stimulated by ASIT. Allergy. 2009;64(5):811-4.

55 Van Overtvelt L, Baron-Bodo V, Horiot S, Moussu H, Ricarte C, Horak F, et al. Changes in basophil activation during grass-pollen sublingual immunotherapy do not correlate with clinical efficacy. Allergy. 2011;66(12): $1530-7$.

56 EAACI Guideline on Allergen Immunotherapy: allergic asthma V 4.0/04 June 2017. Available from: http://www.eaaci.org/documents/A I T/Allergi c_asthma_ AIT_03_06_17.pdf].

57 Cox L, Nelson H, Lockey R, Calabria C, Chacko T, Finegold I, et al. Allergen immunotherapy: a practice parameter third update. J Allergy Clin Immunol. 2011;127(1 Suppl): S1-55.

58 Zuberbier T, Bachert C, Bousquet PJ, Passalacqua $\mathrm{G}$, Walter Canonica $\mathrm{G}$, Merk $\mathrm{H}$, et al. $\mathrm{GA}^{2}$ LEN/EAACI pocket guide for allergenspecific immunotherapy for allergic rhinitis and asthma. Allergy. 2010;65(12):1525-30.

59 Cox L, Jacobsen L. Comparison of allergen immunotherapy practice patterns in the United States and Europe. Ann Allergy Asthma Immunol. 2009;103:451-9.

60 Cirla AM, Cirla PE, Parmiani S, Pecora S. A pre-seasonal birch/hazel sublingual immunotherapy can improve the outcome of grass pollen injective treatment in bisensitized individuals. A case-referent, two-year controlled study. Allergol Immunopathol. 2003; 31(1):31-43.
61 Marogna M, Spadolini I, Massolo A, Zanon P, Berra D, Chiodini E, et al. Effects of sublingual immunotherapy for multiple or single allergens in polysensitized patients. Ann Allergy Asthma Immunol. 2007;98(3):274-80.

62 Maloney J, Berman G, Gagnon R, Bernstein DI, Nelson HS, Kleine-Tebbe J, et al. Sequential treatment initiation with timothy grass and ragweed sublingual immunotherapy tablets followed by simultaneous treatment is well tolerated. J Allergy Clin Immunol Pract. 2016;4(2):301-e2.

63 Demoly P, Passalacqua G, Pfaar O, Sastre J, Wahn U. Management of the polyallergic patient with allergy immunotherapy: a practicebased approach. Allergy Asthma Clin Immunol. 2016;12:2.

64 Canonica GW, Baena-Cagnani CE, Bousquet J, Bousquet PJ, Lockey RF, Malling H-J, et al. Recommendations for standardization of clinical trials with allergen specific immunotherapy for respiratory allergy: a statement of a World Allergy Organization (WAO) taskforce. Allergy. 2007 Mar;62(3): 317-24.

65 Pfaar O, Bachert C, Bufe A, Buhl R, Ebner C, Eng $\mathrm{P}$, et al. Guideline on allergen-specific immunotherapy in IgE-mediated allergic diseases: S2k Guideline of the German Society for Allergology and Clinical Immunology (DGAKI), the Society for Pediatric Allergy and Environmental Medicine (GPA), the Medical Association of German Allergologists (AeDA), the Austrian Society for Allergy and Immunology (ÖGAI), the Swiss Society for Allergy and Immunology (SGAI), the German Society of Dermatology (DDG), the German Society of Oto- Rhino-Laryngology, Head and Neck Surgery (DGHNO-KHC), the German Society of Pediatrics and Adolescent Medicine (DGKJ), the Society for Pediatric Pneumology (GPP), the German Respiratory Society (DGP), the German Association of ENT Surgeons (BV-HNO), the Professional Federation of Paediatricians and Youth Doctors (BVKJ), the Federal Association of Pulmonologists (BDP) and the German Dermatologists Association (BVDD). Allergo J Int. 2014;3(8):282-319.

66 Pajno GB, Bernardini R, Peroni D, Arasi S, Martelli A, Landi M, et al. Allergen-specific Immunotherapy panel of the Italian Society of Pediatric Allergy and Immunology (SIAIP). Clinical practice recommendations for allergen-specific immunotherapy in children: the Italian consensus report. Ital J Pediatr. 2017; 43:13.

67 Dhami S, Nurmatov U, Arasi S, Khan T, Asaria $\mathrm{M}$, Zaman $\mathrm{H}$, et al. Allergen immunotherapy for allergic rhinoconjunctivitis: a systematic review and meta-analysis. Allergy. 2017; 72(11):1597-631..2017 
68 Pfaar O, Bachert C, Bufe A, Buhl R, Ebner C, Eng $\mathrm{P}$, et al. Guideline on allergen-specific immunotherapy in IgE-mediated allergic diseases: S2k Guideline of the German Society for Allergology and Clinical Immunology (DGAKI), the Society for Pediatric Allergy and Environmental Medicine (GPA), the Medical Association of German Allergologists (AeDA), the Austrian Society for Allergy and Immunology (ÖGAI), the Swiss Society for Allergy and Immunology (SGAI), the German Society of Dermatology (DDG), the German Society of Oto-Rhino-Laryngology, Head and Neck Surgery (DGHNO-KHC) the German Society of Pediatrics and Adolescent Medicine (DGKJ), the Society for Pediatric Pneumology (GPP), the German Respiratory Society (DGP), the German Association of ENT Surgeons (BV-HNO), the Professional Federation of Paediatricians and Youth Doctors (BVKJ), the Federal Association of Pulmonologists (BDP) and the German Dermatologists Association (BVDD). Allergo J Int. 2014;23:282-319.

69 Agache I, Lau S, Akdis CA, Smolinska S, Bonini $\mathrm{M}$, Cavkaytar O, et al. EAACI Guidelines on Allergen Immunotherapy: house dust mite-driven allergic asthma. Allergy. 2019; 74(5):855-73.

70 Epstein TG, Liss GM, Murphy-Berendts K, Bernstein DI. AAAAI/ACAAI surveillance study of subcutaneous immunotherapy, years 2008-2012: an update on fatal and nonfatal systemic allergic reactions. J Allergy Clin Immunol Pract. 2014;2(2):161-7.

71 Calderón MA, Vidal C, Rodríguez Del Río P, Just J, Pfaar O, Tabar AI, et al. European Survey on Adverse Systemic Reactions in Allergen Immunotherapy (EASSI): a real-life clinical assessment. Allergy. 2017;72(3):462-72.

72 Incorvaia C, Ridolo E. In the strategies to prevent asthma exacerbations, allergic asthma needs specific treatment. Curr Med Res Opin. 2015;31(4):821-3.

73 Emminger W, Smeenk F, Guzik T, Dyczek A, Fejerskov P, Brodersen R, et al. The SQ HDM SLIT-tablet is well-tolerated in respiratory allergic disease: results from 2 DBPC phase III trials (MERIT and MITRA). Allergy. 2014;69: 184.

74 Asamoah F, Kakourou A, Dhami S, Lau S, Agache I, Muraro A, et al. Allergen immunotherapy for allergic asthma: a systematic overview of systematic reviews. Clin Transl Allergy. 2017;7(7):25.

75 Devillier P, Fadel R, de Beaumont O. House dust mite sublingual immunotherapy is safe in patients with mild-to-moderate, persistent asthma: a clinical trial. Allergy. 2016;71(2): 249-57.

76 Abramson MJ, Puy RM, Weiner JM. Injection allergen immunotherapy for asthma. Cochrane Database Syst Rev. 2010;8(8): CD001186.
77 Erekosima N, Suarez-Cuervo C, Ramanathan M, Kim JM, Chelladurai Y, Segal JB, et al. Effectiveness of subcutaneous immunotherapy for allergic rhinoconjunctivitis and asthma: a systematic review. Laryngoscope. 2014; 124(3):616-27.

78 Wise SK, Lin SY, Toskala E, Orlandi RR, Akdis CA, Alt JA, et al. International consensus statement on allergy and rhinology: allergic rhinitis. Int Forum Allergy Rhinol. 2018;8(2): 108-352.

79 Zhang W, Lin C, Sampath V, Nadeau K. Impact of allergen immunotherapy in allergic asthma. Immunotherapy. 2018;10(7):579-93.

80 Wang L, Yin J, Fadel R, Montagut A, de Beaumont $\mathrm{O}$, Devillier P, et al. House dust mite sublingual immunotherapy is safe and appears to be effective in moderate, persistent asthma. Allergy. 2006;69(9):1181-8.

81 Elliott J, Kelly SE, Johnston A, Skidmore B, Gomes T, Wells GA. Allergen immunotherapy for the treatment of allergic rhinitis and/or asthma: an umbrella review. CMAJ Open. 2017;5(2):E373-85.

82 Lin SY, Azar A, Suarez-Cuervo C, Diette GB, Brigham E, Rice J, et al. The Role of Immunotherapy in the Treatment of Asthma [Internet]. Rockville, MD: Agency for Healthcare Research and Quality (US); 2018 Mar.

$83 \mathrm{Lu}$ Y, Xu L, Xia M, Li Y, Cao L. The efficacy and safety of subcutaneous immunotherapy in mite-sensitized subjects with asthma: a meta-analysis. Respir Care. 2015;60(2):269-78.

84 Polzehl D, Keck T, Riechelmann H. [Analysis of the efficacy of specific immunotherapy with house-dust mite extracts in adults with allergic rhinitis and/or asthma]. Laryngorhinootologie. 2003;82(4):272-80.

85 Tabar AI, Arroabarren E, Echechipía S, García BE, Martín S, Alvarez-Puebla MJ. Three years of specific immunotherapy may be sufficient in house dust mite respiratory allergy. J Allergy Clin Immunol. 2011;127(1):57-3.

86 Dolz I, Martínez-Cócera C, Bartolomé JM, Cimarra M. A double-blind, placebo-controlled study of immunotherapy with grasspollen extract Alutard SQ during a 3-year period with initial rush immunotherapy. Allergy. 1996;51(7):489-500.

87 Walker SM, Pajno GB, Lima MT, Wilson DR, Durham SR. Grass pollen immunotherapy for seasonal rhinitis and asthma: a randomized, controlled trial. J Allergy Clin Immunol. 2001;107(1):87-93.

88 Dahl R, Stender A, Rak S. Specific immunotherapy with SQ standardized grass allergen tablets in asthmatics with rhinoconjunctivitis. Allergy. 2006;61(2):185-90.

89 Durham SR, Walker SM, Varga EM, Jacobson MR, O'Brien F, Noble W, et al. Long-term clinical efficacy of grass-pollen immunotherapy. N Engl J Med. 1999;341(7):468-75.

90 Dominicus R. 3-years' long-term effect of subcutaneous immunotherapy (SCIT) with a high-dose hypoallergenic 6-grass pollen preparation in adults. Eur Ann Allergy Clin Immunol. 2012;44(3):135-40.
91 Alvarez-Cuesta E, Cuesta-Herranz J, Puyana-Ruiz J, Cuesta-Herranz C, BlancoQuirós A. Monoclonal antibody-standardized cat extract immunotherapy: risk-benefit effects from a double-blind placebo study. J Allergy Clin Immunol. 1994;93(3):556-66.

92 Varney VA, Edwards J, Tabbah K, Brewster H, Mavroleon G, Frew AJ. Clinical efficacy of specific immunotherapy to cat dander: a double-blind placebo-controlled trial. Clin Exp Allergy. 1997;27(8):860-7.

93 Kuna P, Kaczmarek J, Kupczyk M. Efficacy and safety of immunotherapy for allergies to Alternaria alternata in children. J Allergy Clin Immunol. 2011;127(2):502-6.

94 Tabar AI, Lizaso MT, García BE, Gómez B, Echechipía S, Aldunate MT, et al. Doubleblind, placebo-controlled study of Alternaria alternata immunotherapy: clinical efficacy and safety. Pediatr Allergy Immunol. 2008; 19(1):67-75.

95 Yukselen A, Kendirli SG, Yilmaz M, Altintas DU, Karakoc GB. Effect of one-year subcutaneous and sublingual immunotherapy on clinical and laboratory parameters in children with rhinitis and asthma: a randomized, placebo-controlled, double-blind, double-dummy study. Int Arch Allergy Immunol. 2012;157(3):288-98

96 Tao L, Shi B, Shi G, Wan H. Efficacy of sublingual immunotherapy for allergic asthma: retrospective meta-analysis of randomized, double-blind and placebo-controlled trials. Clin Respir J. 2014;8(2):192-205.

97 Mener DJ, Lin SY. The role of allergy immunotherapy in the treatment of asthma. Curr Opin Otolaryngol Head Neck Surg. 2016; 24(3):215-20.

98 Marogna M, Spadolini I, Massolo A, Canonica GW, Passalacqua G. Long-lasting effects of sublingual immunotherapy according to its duration: a 15-year prospective study. J Allergy Clin Immunol. 2010;126(5):969-75.

99 Karakoc-Aydiner E, Eifan AO, Baris S, Gunay E, Akturk E, Akkoc T, et al. Long-term effect of sublingual and subcutaneous immunotherapy in dust mite-allergic children with asthma/rhinitis: a 3-year prospective randomized controlled trial. J Investig Allergol Clin Immunol. 2015;25(5):334-42.

100 Ozdemir C, Yazi D, Gocmen I, Yesil O, Aydogan M, Semic-Jusufagic A, et al. Efficacy of long-term sublingual immunotherapy as an adjunct to pharmacotherapy in house dust mite-allergic children with asthma. Pediatr Allergy Immunol. 2007;18(6) 508-15.

101 Lee J, McDonald C. Review: immunotherapy improves some symptoms and reduces long-term medication use in mild to moderate asthma. Ann Intern Med. 2018;169(4): JC17.

102 Compalati E, Passalacqua G, Bonini M, Canonica GW. The efficacy of sublingual immunotherapy for house dust mites respiratory allergy: results of a GA2LEN meta-analysis. Allergy. 2009;64(11):1570-9. 
103 Liao W, Hu Q, Shen LL, Hu Y, Tao HF, Li HF, et al. Sublingual immunotherapy for asthmatic children sensitized to house dust mite: a meta-analysis. Medicine. 2015; 94(24):e701.

104 Calamita Z, Saconato H, Pelá AB, Atallah AN. Efficacy of sublingual immunotherapy in asthma: systematic review of randomized-clinical trials using the Cochrane Collaboration method. Allergy. 2006;61(10): 1162-72.

105 Canonica GW, Bousquet J, Casale T, Lockey RF, Baena-Cagnani CE, Pawankar R, et al. Sub-lingual immunotherapy: World Allergy Organization position paper 2009. World Allergy Organ J. 2009;2(11):233-81.

106 Radulovic S, Wilson D, Calderon M, Durham S. Systematic reviews of sublingual immunotherapy (SLIT). Allergy. 2011;66(6): 740-52.

107 Normansell R, Kew KM, Bridgman AL. Sublingual immunotherapy for asthma. Cochrane Database Syst Rev. 2015;8(8): CD011293.

108 Mosbech H, Deckelmann R, de Blay F, Pastorello EA, Trebas-Pietras E, Andres LP, et al. Standardized quality (SQ) house dust mite sublingual immunotherapy tablet (ALK) reduces inhaled corticosteroid use while maintaining asthma control: a randomized, double-blind, placebo-controlled trial. J Allergy Clin Immunol. 2014;134(3):568-75.e7.

109 de Blay F, Kuna P, Prieto L, Ginko T, Seitzberg D, Riis B, et al. SQ HDM SLIT-tablet (ALK) in treatment of asthma-post hoc results from a randomised trial. Respir Med. 2014;108:1430-7.

110 Gómez J, Flores G, Orea M, López J, Jiménez N. Safety and efficacy of specific sublingual immunotherapy in patients with asthma and allergy to Dermatophagoides pteronyssinus. Rev Alerg Mex. 2005;52:231-6.

111 Voltolini S, Troise C, Incorvaia C, Bignardi D, Di Cara G, Marcucci F, et al. Effectiveness of high dose sublingual immunotherapy to induce a stepdown of seasonal asthma: a pilot study. Curr Med Res Opin. 2010;26(1): 37-40.

112 Demoly P, Makatsori M, Casale TB, Calderon MA. The potential role of allergen immunotherapy in stepping down asthma treatment. J Allergy Clin Immunol Pract. 2017;5(3):640-8.

113 Zhong C, Yang W, Li Y, Zou L, Deng Z, Liu $\mathrm{M}$, et al. Clinical evaluation for sublingual immunotherapy with Dermatophagoides farinae drops in adult patients with allergic asthma. Ir J Med Sci. 2018;187(2):441-6.

114 Lin SY, Erekosima N, Kim JM, Ramanathan M, Suarez-Cuervo C, Chelladurai Y, et al. Sublingual immunotherapy for the treatment of allergic rhinoconjunctivitis and asthma: a systematic review. JAMA. 2013; 309(12):1278-88.
115 Ridolo E, Rogkakou A, Ventura MT, Martignago I, Incorvaia C, Di Lorenzo G, et al. How to fit allergen immunotherapy in the elderly. Clin Mol Allergy. 2017;6(15):17.

116 Cantani A, Micera M. A prospective study of asthma desensitization in 1182 children, 592 asthmatic children and 590 nonatopic controls. Eur Rev Med Pharmacol Sci. 2005; 9(6):325-9.

117 Tsai TC, Lu JH, Chen SJ, Tang RB. Clinical efficacy of house dust mite-specific immunotherapy in asthmatic children. Pediatr Neonatol. 2010;51(1):14-8.

118 Blumberga G, Groes L, Haugaard L, Dahl R. Steroid-sparing effect of subcutaneous SQstandardised specific immunotherapy in moderate and severe house dust mite allergic asthmatics. Allergy. 2006;61(7):843-8.

119 Lambert N, Guiddir T, Amat F, Just J. Pretreatment by omalizumab allows allergen immunotherapy in children and young adults with severe allergic asthma. Pediatr Allergy Immunol. 2014;25(8):829-32.

120 Hedlin G, van Hage M. The role of immunotherapy in the management of childhood asthma. Ther Adv Respir Dis. 2012;6(3): $137-46$.

121 Kopp MV, Hamelmann E, Zielen S, Kamin W, Bergmann KC, Sieder C, et al. Combination of omalizumab and specific immunotherapy is superior to immunotherapy in patients with seasonal allergic rhinoconjunctivitis and co-morbid seasonal allergic asthma. Clin Exp Allergy. 2009;39(2):271-9.

122 Massanari M, Nelson H, Casale T, Busse W, Kianifard F, Geba GP, et al. Effect of pretreatment with omalizumab on the tolerability of specific immunotherapy in allergic asthma. J Allergy Clin Immunol. 2010; 125(2):383-9.

123 Lombardi C, Canonica GW, Passalacqua G. Allergen immunotherapy as add-on to biologic agents. Curr Opin Allergy Clin Immunol. 2018;18(6):502-8.

124 Gülsen A, Wallis S, Jappe U. Combination of immunotherapies for severe allergic asthma. J Asthma. 2019;5:1-4.

125 Rice JL, Diette GB, Suarez-Cuervo C, Brigham EP, Lin SY, Ramanathan M, et al. Allergen-specific immunotherapy in the treatment of pediatric asthma: a systematic review. Pediatrics. 2018;141(5):e20173833.

126 van de Griendt EJ, Tuut MK, de Groot $\mathrm{H}$, Brand PLP. Applicability of evidence from previous systematic reviews on immunotherapy in current practice of childhood asthma treatment: a GRADE (Grading of Recommendations Assessment, Development and Evaluation) systematic review. BMJ Open. 2017;7(12):e016326.

127 Larenas-Linnemann D, Luna-Pech JA. What you should not miss from the systematic reviews and meta-analyses on allergenspecific immunotherapy in 2017. Curr Opin Allergy Clin Immunol. 2018;18(3):168-76.
128 Baris S, Kiykim A, Ozen A, Tulunay A, Karakoc-Aydiner E, Barlan IB. Vitamin D as an adjunct to subcutaneous allergen immunotherapy in asthmatic children sensitized to house dust mite. Allergy. 2014;69(2):24653.

129 Hui Y, Li L, Qian J, Guo Y, Zhang X, Zhang $X$. Efficacy analysis of three-year subcutaneous SQ-standardized specific immunotherapy in house dust mite-allergic children with asthma. Exp Ther Med. 2014;7(3):630-4.

130 Adkinson NF, Eggleston PA, Eney D, Goldstein EO, Schuberth KC, Bacon JR, et al. A controlled trial of immunotherapy for asthma in allergic children. N Engl J Med. 1997; 336(5):324-31.

131 Đurić-Filipović I, Caminati M, Kostić G, Filipović Đ, Živković Z. Allergen specific sublingual immunotherapy in children with asthma and allergic rhinitis. World J Pediatr. 2016;12(3):283-90.

132 Olaguibel JM, Alvarez Puebla MJ. Efficacy of sublingual allergen vaccination for respiratory allergy in children. Conclusions from one meta-analysis. J Investig Allergol Clin Immunol. 2005; 15:9-16.

133 Penagos M, Passalacqua G, Compalati E, Baena-Cagnani CE, Orozco S, Pedroza A, et al. Metaanalysis of the efficacy of sublingual immunotherapy in the treatment of allergic asthma in pediatric patients, 3 to 18 years of age. Chest. 2008;133(3):599-609.

134 Rodriguez-Perez N, Ambriz-Moreno M de J, Canonica GW, Penagos M. Frequency of acute systemic reactions in patients with allergic rhinitis and asthma treated with sublingual immunotherapy. Ann Allergy Asthma Immunol. 2008;101:304-10.

135 Di Rienzo V, Marcucci F, Puccinelli P, Parmiani S, Frati F, Sensi L, et al. Long-lasting effect of sublingual immunotherapy in children with asthma due to house dust mite: a 10 -year prospective study. Clin Exp Allergy. 2003;33(2):206-10.

136 Cools M, Van Bever HP, Weyler JJ, Stevens WJ. Long-term effects of specific immunotherapy, administered during childhood, in asthmatic patients allergic to either housedust mite or to both house-dust mite and grass pollen. Allergy. 2000;55(1):69-73.

137 Pham-Thi N, Scheinmann P, Fadel R, Combebias A, Andre C. Assessment of sublingual immunotherapy efficacy in children with house dust mite-induced allergic asthma optimally controlled by pharmacologic treatment and mite-avoidance measures. Pediatr Allergy Immunol. 2007;18(1):47-57.

138 Keles S, Karakoc-Aydiner E, Ozen A, Izgi AG, Tevetoglu A, Akkoc T, et al. A novel approach in allergen-specific immunotherapy: combination of sublin-gual and subcutaneous routes. J Allergy Clin Immunol. 2011; 128:808-15.
Allergen-Specific Immunotherapy for

Allergic Asthma
Int Arch Allergy Immunol 2021;182:496-514 DOI: $10.1159 / 000513811$ 
139 Schmitt J, Schwarz K, Stadler E, Wüstenberg EG. Allergy immunotherapy for allergic rhinitis effectively prevents asthma: results from a large retrospective cohort study. J Allergy Clin Immunol. 2015;136(6):1511-6.

140 Zielen S, Devillier P, Heinrich J, Richter H, Wahn U. Sublingual immunotherapy provides long-term relief in allergic rhinitis and reduces the risk of asthma: a retrospective, real-world database analysis. Allergy. 2018; 73(1):165-77.

141 Devillier P, Wahn U, Zielen S, Heinrich J. Grass pollen sublingual immunotherapy tablets provide long-term relief of grass pollen-associated allergic rhinitis and reduce the risk of asthma: findings from a retrospective, real-world database subanalysis. Expert Rev Clin Immunol. 2017;13(12): 1199-206.

142 Mener DJ, Lin SY. Improvement and prevention of asthma with concomitant treatment of allergic rhinitis and allergen-specific therapy. Int Forum Allergy Rhinol. 2015; 5(Suppl 1):S45-50.

143 Polosa R, Al-Delaimy WK, Russo C, Piccillo G, Sarva M. Greater risk of incident asthma cases in adults with allergic rinitis and effect of allergen immunotherapy: a retrospective cohort study. Respir Res. 2005;6:153.

144 Grembiale RD, Camporota L, Naty S, Tranfa CM, Djukanovic R, Marsico SA. Effects of specific immunotherapy in allergic rhinitic individuals with bronchial hyperresponsiveness. Am J Respir Crit Care Med. 2000; 162(6):2048-52.

145 Peng H, Li CW, Lin ZB, Li TY. Long-term efficacy of specific immunotherapy on house dust mite-induced allergic rhinitis in China. Otolaryngol Head Neck Surg. 2013; 149(1):40-6.

146 Crimi N, Li Gotti F, Mangano G, Paolino G, Mastruzzo C, Vancheri C, et al. A randomized, controlled study of specific immunotherapy in monosensitized subjects with seasonal rhinitis: effect on bronchial hyperresponsiveness, sputum inflammatory markers and development of asthma symptoms. Ann Ital Med Int. 2004;19(2):98-108.

147 Marogna M, Massolo A, Passalacqua G. Effect of adjuvanted and standard sublingual immunotherapy on respiratory function in pure rhinitis due to house dust mite over a 5-year period. World Allergy Organ J. 2017; 10(1):7.
148 Kristiansen M, Dhami S, Netuveli G, Halken S, Muraro A, Roberts G, et al. Allergen immunotherapy for the prevention of allergy: a systematic review and meta-analysis. Pediatr Allergy Immunol. 2017;28(1):18-29.

149 Novembre E, Galli E, Landi F, Caffarelli C, Pifferi M, De Marco E, et al. Coseasonal sublingual immunotherapy reduces the development of asthma in children with allergic rhinoconjunctivitis. J Allergy Clin Immunol. 2004;114(4):851.

150 Marogna M, Tomassetti D, Bernasconi A, Colombo F, Massolo A, Businco AD, et al. Preventive effects of sublingual immunotherapy in childhood: an open randomized controlled study. Ann Allergy Asthma Immunol. 2008;101(2):206.

151 Moller C, Dreborg S, Ferdousi HA, Halken S, Høst A, Jacobsen L, et al. Pollen immunotherapy reduces the development of asthma in children with seasonal rhinoconjunctivitis (the PAT-study). J Allergy Clin Immunol. 2002;109:251-6.

152 Jacobsen L, Niggemann B, Dreborg S, Ferdousi HA, Halken S, Høst A, et al. Specific immunotherapy has long-term preventive effect of seasonal and perennial asthma: 10year follow-up on the PAT study. Allergy. 2007;62(8):943-8.

153 Niggemann B, Jacobsen L, Dreborg S, Ferdousi HA, Halken S, Høst A, et al. Five-year follow-up on the PAT study: specific immunotherapy and long-term prevention of asthma in children. Allergy. 2006;61(7): 855-9.

154 Valovirta E, Petersen TH, Piotrowska T, Laursen MK, Andersen JS, Sørensen HF, et al. Results from the 5-year SQ grass sublingual immunotherapy tablet asthma prevention (GAP) trial in children with grass pollen allergy. J Allergy Clin Immunol. 2018; 141(2):529-e13.

155 Hankin CS, Cox L. Allergy immunotherapy: what is the evidence for cost saving? Curr Opin Allergy Clin Immunol. 2014;14(4): 363-70.

156 Reinhold T, Ostermann J, Thum-Oltmer S, Brüggenjürgen $B$. Influence of subcutaneous specific immunotherapy on drug costs in children suffering from allergic asthma. Clin Transl Allergy. 2013;3(1):30.

157 Hahn-Pedersen J, Worm M, Green W, Andreasen JN, Taylor M. Cost utility analysis of the SQ $\left.{ }^{\circ}\right)$ HDM SLIT tablet in house dust mite allergic asthma patients in a German setting. Clin Transl Allergy. 2016;6(1):35.
158 Valovirta E, Berstad AK, de Blic J, Bufe A Eng P, Halken S, et al. Design and recruitment for the GAP trial, investigating the preventive effect on asthma development of an SQ-standardized grass allergy immunotherapy tablet in children with grass pollen-induced allergic rhinoconjunctivitis. Clin Ther. 2011;33(10):1537-46.

159 Arroabarren E, Tabar AI, Echechipía S, Cambra K, García BE, Alvarez-Puebla MJ. Optimal duration of allergen immunotherapy in children with dust mite respiratory allergy. Pediatr Allergy Immunol. 2015;26(1):34-41.

160 Lim CE, Sison CP, Ponda P. Comparison of pediatric and adult systemic reactions to subcutaneous immunotherapy. J Allergy Clin Immunol Pract. 2017;5(5):1241-7.e2.

161 Epstein TG, Liss GM, Murphy-Berendts K, Bernstein DI. Risk factors for fatal and nonfatal reactions to subcutaneous immunotherapy: national surveillance study on allergen immunotherapy (2008-2013). Ann Allergy Asthma Immunol. 2016(116):354-9.

162 James C, Bernstein DI. Allergen immunotherapy: an updated review of safety. Curr Opin Allergy Clin Immunol. 2017;17(1):55-9.

163 Petersen KD, Kronborg C, Larsen JN, Dahl R, Gyrd-Hansen D. Patient related outcomes in a real life prospective follow up study: allergen immunotherapy increase quality of life and reduce sick days. World Allergy Organ J. 2013;6(1):15.

164 Calderón MA, Vidal C, Rodríguez Del Río P, Just J, Pfaar O, Tabar AI, et al. EASSI Doctors' Group. European Survey on Adverse Systemic Reactions in Allergen Immunotherapy (EASSI): a real-life clinical assessment. Allergy. 2017;72(3):462-72.

165 Rodríguez Del Río P, Vidal C, Just J, Tabar AI, Sanchez-Machin I, Eberle P, et al. The European Survey on Adverse Systemic Reactions in Allergen Immunotherapy (EASSI) a paediatric assessment. Pediatr Allergy Immunol. 2017;28(1):60-70.

166 Vidal C, Rodríguez Del Río P, Gude F, Casale T, Cox L, Just J, et al. Comparison of international systemic adverse reactions due to allergen immunotherapy. J Allergy Clin Immunol Pract. 2019;7(4):1298-e3.

167 Domínguez-Ortega J, Phillips-Anglés E, Barranco P, Quirce S. Cost-effectiveness of asthma therapy: a comprehensive review. J Asthma. 2015;52(6):529-37. 